\title{
Exploring the Experience of Older Adults Volunteering with an Intergenerational Program to Prevent Childhood Obesity
}

\author{
Danilea Werner ${ }^{1}$, James Teufel ${ }^{2}$ and Stephen Brown ${ }^{3}$ \\ ${ }^{1}$ Auburn University \\ ${ }^{2}$ The OASIS Institute \\ ${ }^{3}$ Southern Illinois University, Carbondale
}

\begin{abstract}
Over the past three decades, obesity rates in the United States have increased dramatically among both children and adults. A variety of programs have been created to prevent and intervene in the obesity epidemic but few are intergenerational. This article explores volunteers' experience with an innovative childhood obesity prevention program called Active Generations. Active Generations benefits both children and seniors by utilizing older adult volunteers to implement a version of the evidence-based childhood obesity prevention program, CATCH (Coordinated Approach To Child Health) in out-ofschool settings. Understanding that social and civic engagement maintains or improves the health of older adults, this article reviews the stories and preliminary experiences of older adults volunteering to help reverse the trend of childhood obesity.
\end{abstract}

(C) 2011 Californian Journal of Health Promotion. All rights reserved.

Keywords: older adults, volunteering, childhood obesity, intergenerational program

\section{Introduction}

Over the past three decades, obesity rates in the United States (U.S.) have increased dramatically. According to the Center for Disease Control and Prevention (CDC), the prevalence of adult obesity has increased in all states, and the rate of obesity has tripled for children ages six to eleven (CDC, 2009; Ogden, Carroll, \& Flegal, 2008). This is especially troubling because, people who were overweight as children are more likely to be obese as adults (Steffen, Dai, Fulton, \& Labarthe, 2009; Hass, Martin, \& Ferris, 2007). Schools, families, and communities must coordinate efforts to integrate physical activity and nutrition education into the community thus decreasing obesity occurrence and impact (Hoelscher, et al., 2010).

This manuscript explores the volunteer experience with a community, childhood obesity prevention program called Active Generations. Active Generations is a dynamic curriculum that impacts multiple generations by utilizing older adult volunteers to implement a version of the evidence-based childhood obesity prevention program, Coordinated Approach To Child Health $(\mathrm{CATCH})$ in out-of-school settings (after-school and summer programs). The CATCH Program, originally known as the Child and Adolescent Trial for Cardiovascular Health was first evaluated in 1991 to 1994 with 96 schools across four states. The original clinical trial, the largest school-based health promotion study ever funded, included a diverse group of over 5,100 students and has been extensively evaluated in over 80 peer-reviewed publications. This inventive program was designed to impact childhood obesity by decreasing saturated fat and sodium in children's diets, and increasing physical activity (Perry et al., 1998; Luepker et al.,1996; Perry et al., 1990). Since the original clinical outcome trial, CATCH and the afterschool version, CATCH Kids Club have been implemented in schools and communities throughout the nation with positive results. 
Researchers have repeatedly found that these programs increase physical activity (Hoelscher, et al., 2010; Kelder et al., 2005) and decrease the risk of childhood obesity (Hoelscher, et al., 2010; Coleman et al., 2005). These researchers are interested in the volunteer experience with implementing an intergenerational version of the CATCH Kids Club program called Active Generations.

\section{History of OASIS and the Partnership with CATCH}

CATCH was created by research teams from the University of California at San Diego, University of Minnesota, Tulane University and University of Texas Health Science Center at Houston. It has scientifically demonstrated that environments can be created that affect healthy behavioral changes in children. As published in the Journal of the American Medical Association, the CATCH Main Trial (19911994) demonstrated that CATCH improved students' self-reported eating and physical activity behaviors (Perry et al., 1998; Luepker et al., 1996). The effects of the CATCH Main trial persisted over three years without continued intervention and have been repeatedly replicated throughout the U.S. (Coleman et al., 2005; Hoelscher, et al., 2010; Kelder et al., 2005).

The OASIS Institute, a national non-profit comprised of a network of centers focused on health and wellness for adults over 50, developed a partnership with the $\mathrm{CATCH}$ program (University of Texas and Flaghouse, Inc.) to introduce Active Generations as a new intergenerational approach to combat both childhood and adult obesity. With funding from the Robert Wood Johnson Foundation, OASIS developed the concept of Active Generations and created strategies to work within their existing national network to implement the program (The OASIS Institute, 2009). Additional funding was provided by the WellPoint Foundation to conduct a two-year pilot of Active Generations in eight cities across the United States. Recognizing that intergenerational programs impact individuals across the lifespan, OASIS viewed the model as appropriate for a multi-level, multi-faceted obesity prevention intervention. What Active
Generations uniquely adds is mentoring by seniors and the reciprocal benefit these seniors receive through the process of volunteering. Using this modified version of the CATCH program, Active Generations, older adults are intended to be the change agents impacting the nutrition and physical activity habits of children as well as giving older adults opportunities to contribute to their communities and improve their well-being by volunteering. Research has documented the health benefits of volunteering for older adults, including reduced mortality (Musick, Herzog, \& House, 1999), increased physical function (Lum \& Lightfoot, 2005), increased levels of self-rated health (MorrowHowell, Hinterlong, Rozario, \& Tang, 2003), muscular strength (Fried et al., 2004), reduced depressive symptomatology (Musick \& Wilson, 2003), reduced pain (Arnstein, Vidal, WellsFederman, Morgan, \& Caudill, 2002), life satisfaction (Van Willigen, 2000); and improved memory and executive function (Carlson, Saczynski, Rebok, et al., 2008).

A major aim of Active Generations is to address the key research that social and civic engagement keeps older adults healthy and active (Lum \& Lightfoot, 2005; Morrow-Howell et al., 2003; Musick \& Wilson, 2003). MorrowHowell, Hong and Tang (2009) found that almost all older adult volunteers felt that the volunteer experience improved their life in some way, with over 20 percent reporting better health. However, the reported feeling of improvement was not isolated to the individual volunteer. Over 90 percent of the volunteers felt that the individuals and community served by the volunteer program was better off because of their service (Morrow-Howell, Hong \& Tang, 2009). There are additional health benefits for volunteers when volunteering involves children and young adults (Hernandez \& Gonzalez, 2008; Tan, Xue, Li, Carlson, \& Fried, 2006) One study found that when Experience Corps volunteers partnered with children, not only did the youth demonstrate improved educational outcomes but the older adults increased physical, cognitive and social activity (Tan, Xue, Li, Carlson, \& Fried, 2006). Another study found that older adult health improved through participation in this civic engagement volunteer 
program (Barron, Tan, Song, McGill, \& Fried, 2009).

\section{Program Description}

Active Generations is an intergenerational nutrition education and physical activity program for children in third through fifth grades. It is implemented in after-school and summer programs by volunteer teams of adults over age 50. Active Generations is comprised of 10 lessons adapted from the $\mathrm{CATCH}$ program, an internationally recognized and well established, childhood obesity prevention program. Except for the first lesson, each class begins with a review of the previous lesson and an introduction to the topic of the day. As one or two volunteers are leading the discussion, another is setting up the healthy snack, a critical part of the program. The students learn how to create the snack in appropriate portions while the volunteers lead a discussion about the snack's nutritional value. To increase child interest in the snacks, they are given fun names such as "Hearty Hearts Steller Sundae," which is a mixture of yogurt, graham crackers and bananas. The interactive snack not only gives the children a chance to create, but also builds

\section{Figure1. Making a nutritious snack} called Ants on a Log

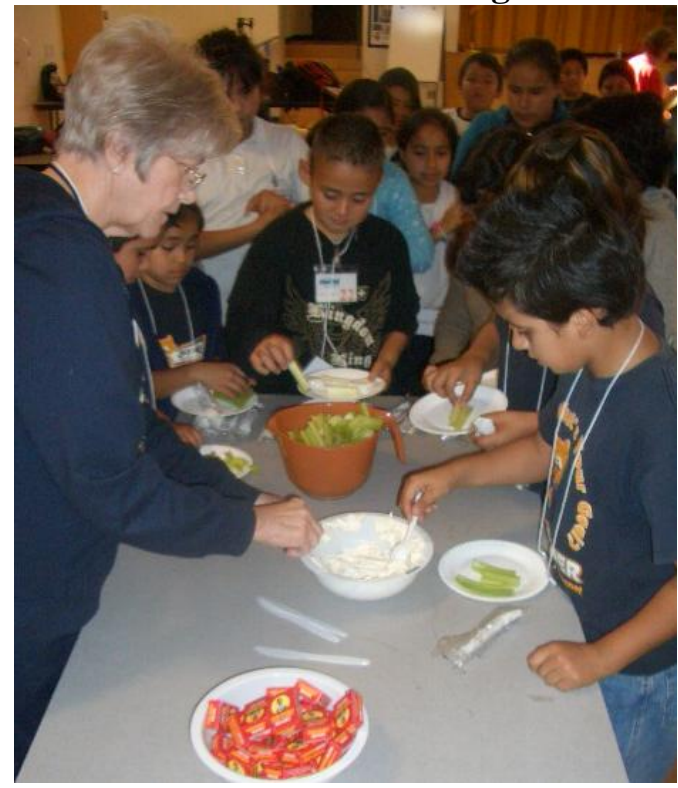

skills and confidence to make the snack at home. The interactive lessons include information on barriers to activity, how to read nutrition labels, getting fruit into breakfast, and many others.

These lessons encourage students to consider their nutrition choices and increase activity levels. After the lesson the students participate in 20 to 30 minutes of physical activity. The games are designed by $\mathrm{CATCH}$ to be allinclusive, non-elimination, fun and challenging. After the activity, the class comes together for a closing review of the day's proceeding. On certain days children are given letters to take home informing their families about the lessons and providing a healthy snack recipe to reinforce nutrition in the home.

\section{Figure 2. A volunteer counts timed sit-ups}

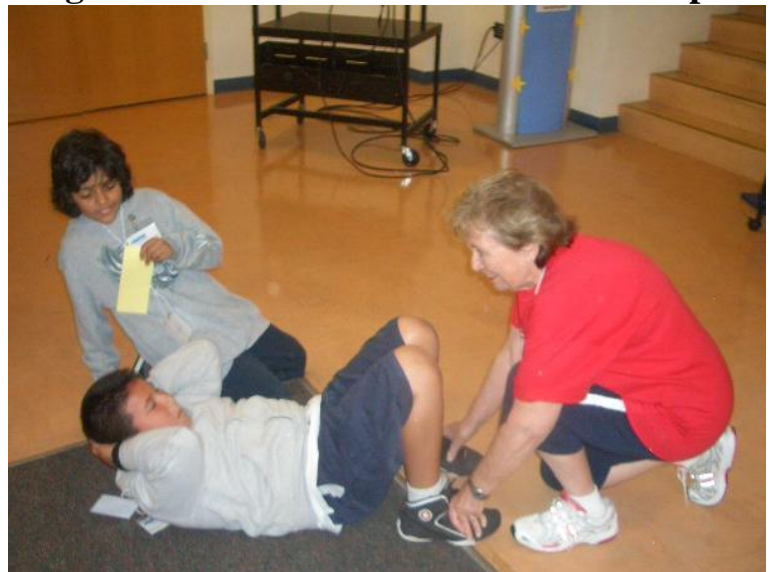

\section{Volunteer Recruitment and Training}

Volunteers are recruited from local community organizations, senior centers, OASIS programs, and local marketing initiatives. Older adult participants typically have an interest in children and health with a desire to make a larger impact for a minimum of one year. Letters and emails are sent to all OASIS participants and announcements are made in community classes. OASIS staff directly reaches out to community organizations and increase program awareness through media such as newspapers and television. Volunteer teams are selected based on program location, interests, ability to 
participate in an eight-hour training session, commitment to complete the program, and potential to lead and motivate other team members and children. A background in teaching, health or fitness is not required.

Active Generations uses the CATCH curriculum, and all volunteers attend Active Generations Volunteer Training. These training sessions cover the rationale, background, and structure of the program and are provided by a certified Active Generations/CATCH trainer. The training offers a chance for volunteers to practice the physical activity portion of the program and ask questions about lessons and implementation. During training the volunteers are introduced to their team. Each team is given time to work out group details including roles and responsibilities, equipment transfer, additional meeting times, and contact information. Once the groups are trained, they are given an assigned program location, date, time, and provided with a program contact, but all other details are left to the group.

Using the self-directed team model, the older adult volunteers are the leaders of Active Generations. Piloted and promoted by the National Council on Aging (NCOA), selfdirected teams are small groups of people who are empowered to manage themselves and their project (National Council on Aging, 2008). The Active Generations volunteers are responsible for planning, managing and implementing the program. This allows for freedom of role choice, implementation pace, and civic engagement. Each member is allowed to negotiate his or her role in the team. For example, some team members like to switch roles; one week leading the interactive lesson and the next leading the physical activity; while some like to choose a responsibility and stay with that task.

\section{Program Implementation}

With a grant from the WellPoint Foundation, OASIS is currently implementing Active Generations in eight U.S. cities in four states. During the first 15 months of implementation, Active Generations reached over 1,000 children and 200 volunteers in eight cities: Albany and Syracuse, NY; Baldwin Hills, Escondido,
Lakewood, and San Diego, CA; Indianapolis, IN; and Saint Louis, MO. Other funding has enabled the implementation of the program in San Antonio, TX, and Pittsburgh, PA. Using an adapted version of the CATCH Kids Club AfterSchool Student Short Questionnaire, a valid and reliable survey instrument, students are assessed by measuring changes in nutrition and physical activity behaviors, knowledge, self-efficacy, and social support before and after the program. Adult volunteers are also surveyed to measure changes in knowledge, attitude and behavior before and after the program. Survey results will be analyzed after the completion of the initial program implementation in late 2011. Volunteers will be encouraged to provide descriptive examples of how volunteering with Active Generations has impacted their lives during all phases of data collection.

\section{Volunteer Experience}

Preliminary data is currently being collected to examine the effect of Active Generations on the volunteer experience. Active Generations volunteers tend to be primarily female $(90 \%)$ of Caucasian $(74.5 \%)$ or African-American $(20 \%)$ descent who have minimally completed high

Figure 3. Volunteers help students complete pre- and post surveys.

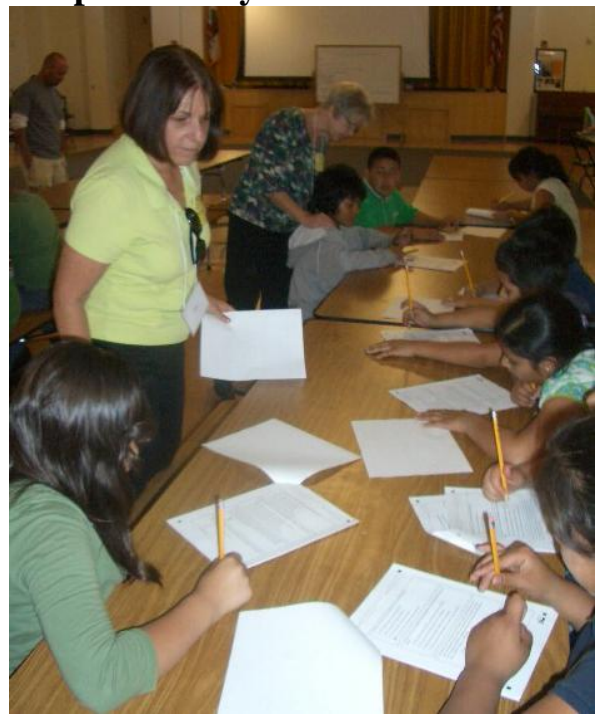

school $(91 \%)$. Also, four out of ten older adult volunteers reported living alone. Early results 
show that adult volunteers increased physical activity, label reading, and self-efficacy in relation to physical activity and nutrition. More detailed results on the impact of Active Generations on both child participants and adult volunteers will be available in late 2011. Perhaps the most compelling preliminary evidence of success comes from volunteers' stories. In Escondido, CA, a volunteer wrote:

As the volunteers and children gathered to participate in the Active Generations Program we did not know quite what to expect, everyone was a little timid at first. We had to answer a health questionnaire, followed by a snack. Mmm, everyone was suddenly interested! We were introduced to Hearty Heart's Journey to Planet Earth, and then the fun began. In the following weeks, we played "GO Activity" charades, broke down the walls that limit our possibilities, learned to read nutrition labels and to discuss healthy living. We tasted veggies of all colors and textures and tried fruit with strange names. Hula hoops and parachutes with balls were our favorite activities; "Dragons Tail Tag" and "See Ya Later Alligator" were our favorite games. It has been a fun filled 8 weeks of learning how to live a healthy life."

In St. Louis, some of the children told volunteers that they had never heard of soy milk or seen a red pepper. Over the course of the program volunteers provided soy milk and a variety of fruits and vegetables for the children to see and try, many for the first time. A few of the children said that they were going to ask their parents to buy some of the new food items. A leader gave another example of how these relationships can develop:

"Mr. John" was one of the first volunteers for the Active Generations Program. He liked the idea of introducing children to healthy choices, his wife told us he needed a reason to "go out and play with the children". John's lessons were delightful and the children giggled at his animation. Being healthy should be fun, he said, and it definitely was! "Mr. John" is very tall and a bit imposing to the students. For weeks we noticed that one of the smallest students couldn't take her eyes off him. Finally, after several sessions she came up to him, put her hand in his and said "Mr. John, how did you get so big?" He laughed and told her he just liked to eat healthy. "I don't know if I want to grow that much," she said.

Finally, one story illuminates the impact Active Generations has on both students and volunteers.

"Ms. Sarah" was the volunteer organizer of the Active Generations Program. The volunteer team looked to her for leadership and was never disappointed. She was our cheerleader and motivator. During the 8 weeks we noticed she had lost a few pounds. "Well," she said, "I can't tell the children to do something I'm not doing; I need to be a good example." Everyone was a winner!

These examples begin to illustrate the impact of Active Generations, but more importantly they exemplify the volunteer experience. Active Generations allows older adults to get involved with their community connecting with children and working on preventing obesity. These volunteers are not just impacting our children, but also their own health and wellness, a key intention of the program.

\section{Discussion}

Providing programs like Active Generations that socially and civically engage older adults is critical, given that the older population in the U.S. is on the verge of a boom. Over the next 25 years, the number of older Americans will double, and older adults will make up a larger portion of the population than ever before in U.S. history. According to the U.S. Census Bureau, between 2000 and 2030, the number of older adults is projected to grow from 35 million to 72 million, eventually representing nearly $20 \%$ of the total population (He, Sengupta, Velkoff \& DeBarros, 2005). This demographic shift will have implications for every community in the country. When the first Baby Boomers turn 65 in 2011, every state will see its 65+ population begin to grow faster than its total 
population (He, Sengupta, Velkoff \& DeBarros, 2005). Providing programs like Active Generations can aid in keeping this growing population involved and active in the community.

Recent advances in health care now give individuals the opportunity to live longer than ever before. Life expectancy is around 78 years of age depending on gender and race/ethnicity (Miniño, Xu, Kochanek \& Tejada-Vera, 2009).

The increase in life expectancy has effectively created an entire additional life phase that did not exist only a few generations ago. Americans now look forward to 20 to 30 years of life after they leave their careers (Morrow-Howell, 2005). Volunteering has become a primary source of remaining engaged in community and social life as individuals' age. According to Rowe \& Kahn (1998) the keys to successful aging include maintaining a low risk for disease, a high level of engagement with one's community, and high physical and cognitive function. They insist that "it is the combination of all three that represents the concept of successful aging fully." Activities that work to enhance these factors include intellectual and creative stimulation, healthy lifestyles and civic engagement. Thus, the broad opportunity to be addressed is having the systems and capacity in place to respond to this dramatically expanding population that is growing in number, living longer and in need of lifelong learning and civic engagement opportunities in order to age successfully. Previous research has also documented the importance of volunteer opportunities being shaped by the knowledge of what can improve the well-being of both the volunteers and society (Morrow-Howell et al., 2003). Active Generations is one program that allows older adults a way to be involved in combating a major social issue; childhood obesity, while improving individual health and wellness.

Following the self-directed teams model, OASIS values the feedback of older adult volunteers. It helps to better integrate the program into served communities as well as improve implementation, a key output of pilot studies. Due to volunteer input, OASIS has begun developing additional lessons, adapting lessons so that they are more age appropriate for the child and older adult participants (creating a kindergarten through second grade curriculum and revising the third through fifth grade curriculum), changing session length from 90 to 60 minutes, increasing the proportion of time dedicated to physical activity, abridging the evaluation surveys where appropriate, increasing the amount of time dedicated to training older adult participants on how to work as a volunteer team, and ensuring that a representative of the host organization is available to handle child disciplinary problems.

OASIS will continue to collect data to fully understand the impact of Active Generations on volunteers and children. Specifically, OASIS looks to establish Active Generations as an evidenced-based program impacting the health of older adults and children. In addition to research, OASIS is invested in expanding Active Generations through community-based partnerships to reach a broad audience. These partnerships are vital to effective dissemination of Active Generations with each partner fulfilling an important role. Typically, OASIS offers the experience of training, delivering, monitoring, and evaluating; while partner organizations provide space, identify participants, and allocate staff and volunteers to facilitate programs. Any potentially interested community is encouraged to contact The OASIS Institute in St. Louis, Missouri.

\section{References}

Arnstein, P., Vidal, M., Wells-Federman, C., Morgan, B., \& Caudill, M. (2002). From chronic pain patient to peer: Benefits and risks of volunteering. Pain Management Nursing, 3, 94-103.

Barron, J.S., Tan, E.J., Yu, Q., Song, M., McGill, S. \& Fried, L.P. (2009). Potential for intensive volunteering to promote the health of older adults in fair health. Journal of Urban Health, 84(4), 641-653. 
Carlson, M.C., Saczynski, J.S., Rebok, G.W., Seeman, T.E., Glass, T.A., McGill, S., ... Fried, L.P. (2008). Exploring the effects of an "everyday" activity program on executive function and memory in older adults: Experience Corps. The Gerontologist, 48(6), 793-801.

Center for Disease Control and Prevention, (2009). Obesity: Halting the epidemic by making health easier: At a glance 2009. Retrieved October, 10, 2009 from http://www.cdc.gov/chronicdisease/resources/publications/AAG/obesity.htm

Center for Disease Control and Prevention \& The Merck Company Foundation. (2007). The State of Aging and Health in America. Whitehouse Station, NJ: Ther Merck Company Foundation.

Coleman, K.J., Tiller, C.L., Sanchez, J., Heath, E.M., Oumar, S., Milliken, G.,\& Dzewaltowski, D.A. (2005). Prevention of the epidemic increases in child risk of overweight in low-income schools. Archives of Pediatrics \& Adolescent Medicine, 159, 217-224.

Fried, L.P., Carlson, M.C., Freedman, M., Frick, K.D., Glass, T.A., Hill, J., ... Zeger, S. (2004). A social model for health promotion for an aging population: Initial evidence on the Experience Corps model. Journal of Urban Health, 81, 64-78.

Hass, J., Lee, L, Kaplan, C., Sonneborn, D., Phillips, K. \& Liang, S. (2003). The association of race, socioeconomic status and health insurance status with the prevalence of overweight among children and adolescents. American Journal of Public Health, 93(12), 2105-2110.

He, W., Sengupta, M., Velkoff, V. \& DeBarros, K. (Dec 2005). 65+ in the United States: 2005. U.S. Census Bureau.

Hernandez, C.R. \& Gonzalez, M.Z. (2008). Effects of Intergenerational interaction of aging. Educational Gerontology, 34; 292-305.

Hoelscher, D.M., Springer, A.E., Ranjit, N., Perry C.L., Evans, A.E., Stigler, M., \& Kelder, S.H. (2010). Reductions in child obesity among disadvantaged school children with community involvement: The Travis County CATCH trail. Obesity, 18, S36-S44.

Kelder, S., Hoelscher, D.M. \& Barroso, C.S., Walker, J.L., Cribb, P., \& Hu, S. (2005). The CATCH Kids Club: A pilot after-school study for improving elementary students' nutrition and physical activity. Public Health Nutrition, 8(2), 133-140.

Lum, T.Y. \& Lightfoot, E. (2005). The effects of volunteering on the physical and mental health of older people. Research in Aging, 27, 31-55.

Luepker RV, Perry, C.L., McKinlay, S.M., Nader, P.R., Parcel, G.S., Stone, E.J., ...Verter, J. (1996). Outcomes of a field trial to improve children's dietary patterns and physical activity: The Child and Adolescent Trial for Cardiovascular Health (CATCH). Journal of the American Medical Association, 275(10), 768-76.

Miniño A.M., Xu J., Kochanek K.D., \& Tejada-Vera B. (2009). Death in the United States, 2007. NCHS data brief, no 26. Hyattsville, MD: National Center for Health Statistics.

Morrow-Howell, N., Hinterlong, J., Rozario, P.A. \& Tang, F. (2003). Effects of volunteering on wellbeing of older adults. Journal of Gerontology. 58B(3), S137-S145.

Morrow-Howell, N. (Feb 15, 2005). Maximizing Civic Engagement of Older Adults. Presentation at the 2005 White House Conference on Aging at Washington University George Warren Brown School of Social Work.

Morrow- Howell, N., Hong, S. I., \& Tang, F. (2009). Who benefits from volunteering? Variations in perceived benefits. The Gerontologist. 49(10), 91-102.

Musick, M.A., Herzog, A.R., \& House, J.S. (1999). The perceived benefits of participation in volunteer and educational activities. Journal of Gerontological Social Work, 32(2), 65-80.

Musick, M.A. \& Wilson, J. (2003). Volunteering and depression: The role of psychological and social resources in different age groups. Social Science \& Medicine, 56, 259-269.

National Council on Aging.(2008). Wisdom Works: Building Better Communities. Fostering Civic Engagement Through Self-Directed Teams 2006-2007 Program Report. Washington D.C.: Metlife Foundation.

OASIS Institute, The (2009). Active Generations Replication Toolkit. St. Louis, MO: The OASIS Institute. 
Ogden, C.L., Carroll, M.D., \& Flegal, K.M.(2008). High body mass index for age among U.S. children and adolescents, 2003-2006. Journal of the American Medical Association, 299(20):2401-2405.

Perry, C.L., Lytle, L.A., Feldman, H., Nicklas, T., Stone, E., Zive M., Garceau, A., \& Kelder, S.H. (1998). The effects of the Child and Adolescent Trial for Cardiovascular Health (CATCH) on fruit and vegetable intake. Journal of Nutrition Education, 30(6), 354-360.

Perry, C. L., Stone, E.J., Parcel, G.S., Ellison, R.C., Nader, P.R., Webber, L.S., \& Luepker, R.V. (1990). School-based cardiovascular health promotion: The child and adolescent trial for cardiovascular health (CATCH). Journal of School Health, 60(8), 406-413.

Rowe, J., Kahn, R. (1998). Successful Aging. New York: Random House.

Steffen, L., Dai, S., Fulton, J. \& Labarthe, D. (2009). Overweight in children and adolescents associated with TV viewing and parental weight: Project HeartBeat! American Journal of Preventative Medicine, 37, S50-S55.

Tan, E., Q.L. Xue, T. Li, M. Carlson, and L. Fried. (2006). Volunteering: A physical activity intervention for older adults - The Experience Corps program in Baltimore. Journal of Urban Health: Bulletin of the New York Academy of Medicine, 83, 954-969.

Van Willigen, M. (2000). Differential benefits of volunteering across the life course. Journals of Gerontology Series B: Psychological Sciences and Social Sciences, 55B, S308-S318.

\author{
Author Information

